\title{
Diálogos entre o patrimônio, a educação e o turismo: um estudo sobre o projeto prazer em conhecer, orgulho em preservar
}

\author{
Dialogues between heritage, education and tourism: a study of the \\ project "prazer em conhecer, orgulho em preservar"
}

\begin{abstract}
Diálogos entre el patrimonio, la educación y el turismo: un estudio sobre el proyecto "prazer em conhecer, orgulho em preservar"
\end{abstract}

\author{
Heidi Gracielle Kanitz \\ Professora na Universidade Federal do Piauí (UFPI) \\ Mestre em Administração (UFRN) \\ Bacharel em Turismo (UFRN) \\ heidikanitz@ufpi.edu.br
}

Data de Submissão:26/05/2017 - Data de Aceite:11/12/2017

\begin{abstract}
Resumo: O objetivo dessa investigação é descrever o projeto "Prazer em Conhecer, Orgulho em Preservar", desenvolvido na cidade de Parnaíba (Piauí, Brasil), apresentando a educação patrimonial como uma ferramenta importante no processo de preservação e conservação do patrimônio edificado. A pesquisa tem cunho qualitativo, de caráter exploratório e descritivo, ancorada em pesquisas bibliográficas e documentais. Apresenta como principais resultados que o projeto, por meio das discussões geradas em sala de aula e em conjunto com a visita guiada, contribuiu para uma análise crítica acerca do patrimônio visitado, seu atual estado de conservação, bem como suscitou questionamentos sobre de que maneira cada aluno pode influenciar direta e indiretamente no processo de salvaguarda do seu patrimônio. Por fim, a preservação e a conservação desses testemunhos do passado se revela importante também para a atividade turística, pois não se pode pensar em potencializar o turismo em local que é descrente de si mesmo.
\end{abstract}

Palavras-chave: educação patrimonial; responsabilidade compartilhada; turismo; Parnaíba.

Abstract: The aim of this research is to describe the project "Prazer em Conhecer, Orgulho em Preservar"
(Pleasure in Knowing, Pride in Preserving) developed in the city of Parnaíba (Piauí, Brazil), presenting
heritage education as an important tool in the process of preservation and conservation of the built
heritage. This is a qualitative study, using exploratory and descriptive methods, based on bibliographic
and document research. The main results are that the project, through the discussions generated in the
classroom and in conjunction with the guided tour, contributed to a critical analysis of the heritage visited
and its current state of conservation. It also raised questions about how each student can influence the 
process of safeguarding the cultural heritage, whether directly or indirectly. Finally, the preservation and conservation of these testimonies of the past are also important for tourism, as how can tourism potential of a place be enhanced if the place does not believe in itself?

Keywords: heritage education; shared responsibility; tourism; Parnaíba.

Resumen: El objetivo de esta investigación es describir el proyecto "Prazer em Conhecer, Orgulho em Preservar" (Placer en Conocer, Orgullo en Preservar), desarrollado en la ciudad de Parnaíba (Piauí, Brasil), presentando la educación patrimonial como una herramienta importante en el proceso de preservación y conservación del patrimonio edificado. La investigación tiene cuño cualitativo, de carácter exploratorio y descriptivo, anclado en investigaciones bibliográficas y documentales. Presenta como principales resultados que el proyecto, por medio de las discusiones generadas en clase y en conjunto con la visita guiada, contribuyo para un análisis crítico acerca del patrimonio visitado, su actual estado de conservación, origino cuestionamientos sobre de qué manera cada alumno puede influenciar directa e indirectamente en el proceso de salvaguarda de su patrimonio. Por fin, la preservación y la conservación de estos testimonios del pasado se revela importante también para la actividad turística, pues no se puede pensar en potencializar el turismo en un lugar que es descreído de sí mismo.

Palabras clave: educación patrimonial; responsabilidad compartida; turismo; Parnaíba.

\section{Introdução}

Tantas vezes dita, soa diluída a assertiva de que tudo o que é público deve ser cuidado a partir da comunidade. É possível verificar, no Brasil, que impera no senso comum a ideia de que o que é individual deve ser cuidado pelo indivíduo; o que é coletivo, fica a cargo dos entes governamentais. Entre tantos elementos, o patrimônio cultural é um bem coletivo pouco sujeito à apropriação pela coletividade, caso não haja um trabalho de base, fundado no saber (Barreto, 2010).

Embutidas no conceito de patrimônio estão presentes dimensões amplificadas no que se entende por cultura. Assim, todas as formas de representação, todos os fazeres e saberes de um povo em seu conjunto é cultura e, portanto, são objetos de valorização patrimonial que devem estar integrados aos objetivos educacionais, preservacionistas, conservacionistas. Não apenas obras arquitetônicas monumentais, de apelo evocativo e comemorativo aos grandes feitos do passado, antiguidades, de valor estético, mas aquilo que tem significado para uma sociedade, o que "contribui para a construção de sua identidade cultural e o exercício da cidadania." (Oriá, 2001: 138)

Diante da pluralidade presente na concepção de patrimônio em suas dimensões políticas, sociais, culturais, econômicas, naturais, a educação patrimonial passa a integrar uma área a ser explorada no universo do conhecimento e das políticas públicas de proteção à vida em seu sentido socioambiental. Especialmente em se tratando de um país como o Brasil, ainda carente de ações mais enfáticas de proteção do seu patrimônio cultural, social e natural, e particularmente em Parnaíba, cujas ações se constituem ainda tímidas para a problemática presente nas cidades incluídas no circuito de visitações, pesquisas, estudos acadêmicos sobre história, cultura, economia, meio ambiente, turismo.

O município de Parnaíba está localizado ao norte do Piauí, na região do Delta do Rio Parnaíba, e dista $339 \mathrm{~km}$ da capital do Estado, Teresina. Atualmente, o número total de habitantes se aproxima de 150 mil, de acordo com o último levantamento do Instituto Brasileiro de Geografia e Estatística (IBGE), feito em 2010. Destaca-se no contexto regional por sua atividade comercial e industrial, e o setor de serviços, em especial o Turismo, vem ganhando maior visibilidade desde a criação da Rota das Emoções. ${ }^{1}$ Um dos principais atrativos turísticos do município é o seu Conjunto Histórico e Paisagístico, tombado pelo Instituto do Patrimônio Histórico e Artístico Nacional (IPHAN) desde 2011, o qual é composto por seis conjuntos: Santa Casa; Avenida Getúlio Vargas;

1 A Rota das Emoções é um roteiro integrado que nasce no âmbito do Programa de Regionalização do Turismo. Envolve 14 municípios dos estados do Maranhão, Piauí e Ceará e é constituída por uma área de 10.477 km². Abarca as áreas de três parques nacionais: o Parque Nacional dos Lençóis Maranhenses (MA), a Área de Proteção Ambiental do Delta do Parnaíba (PI) e o Parque Nacional de Jericoacoara (CE). Fonte: Ministério do Turismo, disponível em: http://turismo.gov.br. 
Praça Santo Antônio; Estação Ferroviária; Praça da Graça e; Porto das Barcas e Galpões Portuários. Essa fragmentação foi definida de acordo com as características arquitetônicas e urbanísticas de cada monumento.

Apesar desse processo e do reconhecimento da cidade como potencial para o desenvolvimento do turismo cultural, ainda são frágeis os laços de pertencimento, orgulho e valorização da sua história por parte dos munícipes, bem como o estado de preservação e conservação do seu patrimônio se encontra prejudicado pela ausência de políticas mais efetivas tanto por parte do poder público como por parte dos órgãos educacionais e população em geral. A preocupação com o patrimônio e com a manutenção da memória de um lugar deve ser constante e responsabilidade de toda a população, não atendendo apenas a interesses específicos ou sendo considerada como tema secundário. Tal como reflete Bou (2012, p.171),

Para que eso sea posible, se debe cooperar y no competir, y sobre todo, no perder nunca de vista lo que verdadeiramente importa: nuestro património y su conservación. Esta reflexión parece obvia pero hay que rescatarla porque en muchas ocasiones uno puede desorientarse y buscar excusas al abandono del património echando la culpa a las administraciones locales y sus ajustados presupuestos económicos, a los ciudadanos porque ni siquiera reconocen su propio património [...].

Há duas situações que se apresentam como fatores-chave e que se aplicam à realidade de Parnaíba, bem como de outras cidades: situações de asfixia em que os municípios se veem diante de uma lista cada vez mais complexa e ampla de novos elementos a considerar como patrimônio local, em um estado de conservação deplorável ou diretamente em estado de ruína e abandono e que devem recuperar em tempo recorde; os próprios cidadãos que desconhecem e, portanto, não podem valorizar, tampouco respeitar porque não possuem ferramentas de aproximação ou um relacionamento mais próximo com o patrimônio. Tal como dito anteriormente, a noção de patrimônio como herança individual parece clara, mas não está tanto na coletividade. A população em geral deve participar, porque não se pode ter uma política de valorização "se as pessoas não tem claro o que se vai fazer, o porquê e para que essas medidas são necessárias se essa mesma população não assimila o conceito do local como uma unidade territorial.” (Bou, 2012: 172)

Diante de tais questões, evidencia-se a importância da educação patrimonial como uma ferramenta de aproximação e reconhecimento do patrimônio de uma localidade por seus moradores, assim como reforça a compreensão acerca da necessidade de se preservar e/ou conservar este patrimônio edificado para as futuras gerações, fazendo com que a responsabilidade pela valorização e manutenção dessa memória seja compartilhada por todos, comunidade e visitantes. A partir desse entendimento, surge este artigo, que pretende discutir a educação patrimonial como uma ferramenta de auxílio à preservação e/ou à conservação ${ }^{2}$, tendo como base o estudo de um projeto desenvolvido em Parnaíba, Piauí, Brasil.

\section{Considerações sobre a tríade preservação do patrimônio, educação patrimonial e turismo}

O turismo entendido como um dos principais fatores do trânsito ou da mobilidade humana configura-se como uma atividade marcadamente cultural, impulsionado pelo desejo dos grupos sociais em vivenciar experiências diferenciadoras de seu cotidiano, projetando, dessa forma, o patrimônio cultural como instrumento mediador de aprendizagem e educação (Costa, 2009).

Neste cenário, sendo o turismo uma área em que o diálogo com o patrimônio se faz de maneira próxima e constante, tem sido visto pela sociedade por meio de duas visões principais: uma paranoica e outra utilitarista (Canclini, 1999). A primeira aponta apenas os aspectos negativos da atividade, destacando a transformação da cultura em mercadoria e o alijamento da comunidade de sua própria cultura. A segunda defende o turismo, centrando-se na geração de riqueza e renda que este 2 Para fins deste estudo, compreendem-se preservação e conservação a partir de Sá (apud Sarmento, 2003): PRESERVAÇÃO: é uma consciência, mentalidade, política (individual ou coletiva, particular ou institucional), com o objetivo de proteger e salvaguardar o Patrimônio. Resguardar o bem cultural, prevenindo possíveis malefícios e proporcionando a este condições adequadas de "saúde". CONSERVAÇÃO: Conjunto de intervenções diretas, realizadas na própria estrutura física do bem cultural, com a finalidade de tratamento, impedindo, retardando ou inibindo a ação nefasta ocasionada pela ausência de uma preservação. 
provoca. No entanto, ao lado dessas duas visões hegemônicas, emergem as discussões sobre 'um outro turismo possível' (Gastal \& Moesch, 2004) e sobre um 'turismo humanizado' (Krippendorf, 2003). Nesta perspectiva, importa pensar as possibilidades do turismo em: proporcionar riqueza de forma mais justa; divulgar a cultura de forma menos massificada; possibilitar o encontro cultural; incluir diferentes grupos nos espaços de lazer; promover a educação patrimonial para turistas e comunidade local; ser uma ferramenta de apropriação da comunidade sobre seu espaço, fomentando a cidadania; entre outras.

Ao identificar o patrimônio é necessário também realizar ações para a sua conservação e valorização, e o turismo aparece como recurso de promoção dessas práticas. Nesse sentido, é estabelecida em 1999, a Carta Internacional de Turismo Cultural em que, segundo César e Stigliano (2010: 82), "[...] são propostos princípios a respeito do turismo e do patrimônio. Reforçase o valor da atividade turística na conservação e como situação econômica, de educação e de conscientização. Esse documento ressalta, ainda, a necessidade de inserção das comunidades locais como beneficiárias da atividade". É neste ínterim que a experiência aqui relatada se insere.

Para Carvalho (2012), o turismo é fator de articulação econômica e territorial que faz com que o patrimônio seja valorizado por meio de estratégias de requalificação e revitalização dos tecidos urbanos, com as novas formas de turismo e novos segmentos da procura turística. Dessa forma, de acordo com Fernandes e Carvalho (2003: 199), o turismo pode ser entendido "[...] como uma estratégia para garantir a valorização e preservação do patrimônio, na medida em que através dele se poderiam incentivar na população atitudes a favor do seu conhecimento e preservação".

O turismo cultural busca proporcionar o conhecimento e a valorização de bens culturais, além de estimular ações de conservação, aproximando a comunidade de seus lugares de memória e representações tradicionais. $\mathrm{O}$ contato entre a cultura da comunidade receptora com um grupo social diferente pode vir a engrandecer a manifestação de pertencimento por tais costumes, ao mesmo tempo em que pode proporcionar desenvolvimento local.

De acordo com a Organização Mundial do Turismo, o turismo cultural é um movimento de pessoas em busca de motivações essencialmente culturais, tais como excursões de estudo, teatralizações e excursões culturais, viagens para festivais e outros eventos culturais, visita a localidades e monumentos, viagens para estudar a natureza, folclore ou arte e peregrinações. Este segmento aparece, portanto, como uma vertente que dá sentido ao uso do patrimônio, atribuindolhe, dentre outras coisas, um valor econômico, transformando os bens, produto do esforço humano, em mercadoria e proporcionando desenvolvimento às localidades. Esse segmento do turismo visa alargar os horizontes deste turista que procura conhecimentos e emoções por meio da descoberta de um patrimônio e do seu território. São diversas as áreas que podem ser exploradas por meio do turismo cultural, a saber: história, religião, gastronomia, artesanato, arte, desporto, termalismo, eventos, agricultura, dentre outras (Mendes, 2009).

Este segmento baseia-se na produção material e espiritual de uma comunidade, ou seja, transita em torno dos patrimônios culturais apropriados e recriados na dinâmica social, por meio da formatação de roteiros, produtos e atrações. Existe uma relação intrínseca entre turismo, memória e patrimônio cultural, na medida em que os valores simbólicos, as relações identitárias, a vivência cotidiana e festiva dos grupos sociais apresentam-se como importantes recursos ou atrativos a serem transformados em produtos turísticos. Paralelamente, o turismo é identificado como suscitador do sentimento de pertença da comunidade em relação ao seu patrimônio, estimulando a conservação da memória e da identidade cultural (Barretto, 2006).

A partir deste sentimento de identidade com o local de residência é que ações de preservação e conservação do patrimônio podem serdesenvolvidas e neste sentido o turismo cultural pode vir a ser um colaborador. Tal como afirma Gomes et al. (2015: 469), "o turismo não é o principal agente de proteção e dinamização do patrimônio, tampouco é o grande vilão da transformação do patrimônio em mercadoria, ele faz parte destas dinâmicas e pode ter diferentes resultados dependendo da forma como é planejado e executado".

A consciencialização junto à população sobre a importância da preservação do patrimônio é fundamental e, nesse sentido, a promoção do turismo aparece como um contributo para esse objetivo, pois as atividades turísticas valorizam os lugares, além de contribuir economicamente 
e socialmente. Assim, Araújo (2007: 02) defende que "o turismo pode capturar as características econômicas do patrimônio e dedicá-la à conservação, gerando fundos, educando a comunidade e influenciando a política".

Diante de taisfatos, percebe-sequeapreservação e a conservação requerem o envolvimento de áreas variadas, ou seja, exige interdisciplinaridade. O sucesso das ações depende, inclusive, de uma 'mudança de mentalidade' (Guichen, 1999). As questões discutidas neste artigo vão além do patrimônio em si e da sua contemplação: abrange o relacionamento (ou a falta de) das pessoas com o que está visível, a compreensão acerca de sua importância.

Acredita-se que um dos pilares que possam nortear a preservação e a conservação dos patrimônios edificados é o entendimento do bem cultural por parte do seu público consumidor, seja ele partícipe da vida daquela comunidade ou apenas um visitante temporário e, a partir disto, as relações que possam surgir dessa interação. Tal entendimento pode ser suscitado a partir de ações de educação para o patrimônio. A prevenção nasce a partir da educação, o ato de preservar está relacionado à consciência cultural do valor de algo. Sendo assim, para que se possa preservar/ conservar, faz-se necessário conhecer o valor do bem cultural, por meio da educação formal ou informal. Urge, portanto, uma necessidade de que haja um real entendimento da importância do significado desses bens, para evitar que o patrimônio se torne um mero objeto de consumo (Scifoni, 2006), principalmente quando se pensa na relação patrimônio e turismo.

Nas cidades, o consumo cultural dos lugares também transformou o patrimônio em objeto de discussão entre o valor simbólico e o valor econômico dos seus bens. Meneses (1999) atribui este conflito principalmente ao turismo, devido a sua responsabilidade pela atual transformação do valor cultural em valor de mercado, uma vez que se propõe à fruição apenas visual dos lugares, eliminando o sentido cotidiano de cultura, juntamente aos significados e às simbologias que representam aquilo que pertence ao universo maior e mais profundo do habitante. Para Choay (2015: 211), "A metamorfose de seu valor de uso em valor econômico ocorre graças à engenharia cultural, vasto empreendimento público e privado, a serviço do qual trabalham grande número de animadores culturais, profissionais da comunicação, agentes de desenvolvimento, engenheiros, mediadores culturais. Sua tarefa consiste em explorar os monumentos por todos os meios, a fim de multiplicar indefinidamente o número de visitantes".

Como afirmado anteriormente, a noção de patrimônio como herança individual parece clara, mas não tanto quando se refere ao plano coletivo, sendo a educação patrimonial um meio para se transformar essa realidade. Sendo assim, de acordo com Bou (2012, p.175):

Esta visión cambiará cuando se el ciudadano tenga la información necesaria para que pueda valorar por él mismo los daños que suponen una mala gestión de éste. Además, si se le brinda la oportunidade de reaccionar ante estas señales construyendo alternativas nuevas, se consigue mayor transversalidad a la hora de la mejora de las soluciones propuestas. La implicación de los ciudadanos hace que se identifiquen los problemas lo que permite dar soluciones que se adapten mejor a las necesidades de cada caso. Este estado se consigue unicamente mediante la dinamización, implicación, movilización y articipación de una cuidadanía informada, reflexiva y motivada. Nace así una solidaridad transgeneracional. Es evidente que el património es cosa de todos y no tiene sentido al margen de la sociedad.

Os bens histórico-culturais representam a identidade de cada povo. Para Lemos (1982), os bens culturais, aos quais ele chama de artefatos, representam uma das categorias do patrimônio cultural, ao lado do meio ambiente e dos saberesfazeres. Estes artefatos representam a interação do homem com o meio, resultando em testemunhos materiais que variam desde objetos até construções e seu entorno. Tuan (1983) remarca que a arquitetura de uma cidade revela, instrui, e atende a um propósito educacional de explicar uma visão da realidade, seja ela atual ou passada, pois em algumas cidades as construções arquitetônicas (seus artefatos) são os primeiros textos a transmitir uma tradição. É possível inferir, portanto, que uma cidade antiga guarda um acervo de fatos cujos cidadãos e suas respectivas gerações podem se inspirar e recriar sua concepção e imagem de lugar (Tuan, 1983). 
Sabe-se que a memória pode ser entendida como a capacidade de relacionar um evento atual com um evento passado, portanto é a capacidade de evocar o passado por meio do presente. $\mathrm{Na}$ capacidade de relacionar as vivências do passado com as do presente, traz a habilidade de criar conhecimentos, histórias, costumes, rituais e hábitos. Faz com que se possa sentir familiarizado com determinado ambiente, trazendo a sensação de saber a qual local se pertence, ou seja, dá a identidade sociocultural. A memória é sempre atual, pois a qualquer momento se pode evocá-la (Motta, 1998).

Para Fernandes (1993), os lugares e os suportes da memória, como museus, monumentos históricos, arquivos, bibliotecas, sítios históricos, vestígios arqueológicos, são os espaços privilegiados no processo educativo para se "desenvolver a sensibilidade e a consciência dos educandos e dos cidadãos para a importância da preservação desses bens culturais." Neste sentido, segundo o mesmo historiador, a educação patrimonial, como proposta interdisciplinar de ensino voltada para questóes atinentes ao patrimônio cultural,

Compreende desde a inclusão, nos currículos escolares de todos os níveis de ensino, de temáticas ou de conteúdos programáticos que versem sobre $\mathrm{o}$ conhecimento e a conservação do patrimônio histórico, até a realização de cursos de aperfeiçoamento e extensão para os educadores e a comunidade em geral, a fim de lhes propiciar informações acerca do acervo cultural, de forma a habilitá-los a despertar, nos educandos e na sociedade, o senso de preservação da memória histórica e o conseqüente interesse pelo tema. (FERNANDES, 1993, p. 273-274)

A utilização das noções de educação patrimonial na sala de aula segue as mesmas premissas da utilização dos conceitos na vida cotidiana: instigar nos discentes a conscientização da importância dos bens patrimoniais, para que se sintam integrados a este, passando a valorizá-los e evitando o vandalismo, pois, dessa forma, estariam fazendo um bem a si mesmos. A iniciativa de utilizar esse conceito em escolas é interessante, pois "os Centros Históricos de muitas cidades do Brasil são excelentes para estimular o professor e os alunos a estabelecer e compreender as relações fundamentais entre o presente, o passado, as mudanças ocorridas nos modos de vida das pessoas que nele viveram, assim como nas próprias cidades. O professor e seus alunos têm a possibilidade de aprender juntos sobre o Centro Histórico, já que este permite um amplo campo de investigação, que desperta interesse tanto numa criança nos primeiros anos de aprendizagem, como no adolescente do $2^{\circ}$ grau. [...]" (Horta, Grunberg \& Monteiro, 1999: 26).

Dessa forma, professores e alunos formam o seu conhecimento de forma integrada, agregando saberes e proporcionando a inserção e o reconhecimento dos discentes no processo de formação cultural local. Esta identificação estimula o processo de preservação de forma endógena, despertando no próprio aluno o desejo de manutenção de um patrimônio que também é seu.

\section{Breve retrospecto histórico da área de estudo}

Parnaíba possui um sítio histórico com a particularidade de condensar diversos períodos históricos e configurações urbanísticas em uma área pouco extensa, estruturado pela Avenida Presidente Vargas, que representava a diversidade física e funcional deste núcleo urbano originado no século XVIII.

De acordo com Da Costa (1974), a cidade de Parnaíba, o mais importante centro urbano da região norte do estado do Piauí, teve origem na vila de São João do Parnaíba, a qual foi fundada em 1762, por João Pereira Caldas, governador da então capitania de São José do Piauí, obedecendo à ordem específica da Carta Régia de 1761, que criava sete vilas em território piauiense, a partir de povoações já existentes, e elevava Oeiras à condição de sede da capitania.

Em 1770, a vila de São João da Parnaíba, implantada no pequeno lugarejo de Testa Branca, foi transferida para o Porto das Barcas, feitoria próspera dominada pelas charqueadas, localizada às margens do Rio Igaraçu, um dos braços com que o Rio Parnaíba forma seu delta para lançar-se no Atlântico.

Testa Branca era uma localidade de somente quatro fogos, oito moradores livres e onze escravos; enquanto o Porto das Barcas era mais povoado, contando com estabelecimentos comerciais, armazéns e casas para oficinas. Sendo muito próximo da povoação, havia o inconveniente da 
insalubridade provocada pelo preparo da carne e o do processamento da sola. A escolha de Testa Branca pelas autoridades foi consequência da busca de um local mais salubre, preocupação que já se tornara habitual entre os portugueses, mas o aspecto econômico, visado pela indústria e pelo comércio, acabaria por predominar na efetivação da escolha do local político e administrativo (Figueiredo \& Monteiro, 2008).

O Porto das Barcas tem sua história ligada à figura de Domingos Dias da Silva, rico português que se instalou na região em meados do século XVIII, vindo do sul da colônia, e que se tornou proprietário de fazendas, charqueadas e várias embarcações que faziam o comércio entre a capitania e outros portos brasileiros. Além do comércio que mantinha com o Pará, o Maranhão, Pernambuco, a Bahia e o Rio de Janeiro, Domingos Dias da Silva exportava, anualmente, toneladas de charque para a Europa. Como consequência do poder econômico herdado dele, seus descendentes também desempenharam papel influente na história político-administrativa da capitania.

Segundo Mott (1985), dentre os documentos do século XVIII consagrados ao Piauí que eram conhecidos até aquela data, o relatório do ouvidormor Antônio José de Morais Durão, intitulado "A Descrição da Capitania de São José do Piauí", de 1772, é o mais completo e traz informações preciosas sobre a vida socioeconômica sertaneja. Por alguns trechos, pode-se depreender que a vila denotava certa prosperidade, devido ao intenso movimento de exportação para vários portos, do norte e do sul do país. Era um "empório comercial com uma estrutura urbana consolidada, merecendo destaque a igreja matriz, que, embora sem cobertura, era uma edificação sólida de cantaria, com linhas magníficas, na qual foram gastos 200 contos de réis" (Mott, 1985: 30-31).

Por outro lado, Da Costa (1974) explica que partedadescriçãodaviladestaca-lhe ainsalubridade, apontando como causa a proximidade dos abatedouros e curtumes. Tal fato explicava a preocupação dos administradores portugueses com a instalação de currais e matadouros longe das casas, decisão anteriormente tomada na criação da Vila de Aracati, no Ceará. Ao mesmo tempo, evidenciava que as prescrições do modelo adotado como protótipo do desenvolvimento urbano, sancionado pela Coroa, nem sempre prevaleceu sobre as razões e os costumes locais.
A produção e o uso da arquitetura dos núcleos urbanos coloniais baseavam-se no trabalho escravo, e a Vila de São João da Parnaíba, como as demais do século XVIII, era limitada pelo nível tecnológico primário, baseado nesse tipo de mão de obra. Tinha dimensões reduzidas e se apoiava no mundo europeu e no mundo rural circundante para a solução de seus problemas de abastecimento. As ruas apresentavam um aspecto uniforme, com casas térreas e assobradadas, construídas sobre o alinhamento das vias públicas e sobre os limites laterais dos terrenos. Essas características decorriam das antigas tradições urbanísticas de Portugal, transmitidas, entre outras formas, pelas disposições legais, como se verificou no Piauí (Figueiredo, 2001).

O comércio se instala como ponto forte da economia da Vila de Parnaíba na segunda metade do século XVIII, tendo como base de escoamento das mercadorias a navegação fluvial e marítima, que recebeu considerável impulso com a criação da alfândega, em 1822, por D. João VI. Em 1844, a Parnaíba foi elevada à categoria de cidade, constituindo-se em um dos principais polos econômicos do estado.

No início do século XX, a vocação comercial exportadora, inicialmente marcada pela produção do charque e, depois, do algodão, do fumo, do couro e de sementes de origem extrativista, cresce, com o comércio internacional da cera de carnaúba, de amêndoas e de óleos. Tal vocação, associada à localização estratégica, fez de Parnaíba a única cidade do Piauí a manter permanente contato tanto com a cultura europeia e a do sul do país, durante os séculos XVIII e XIX, e com a americana, durante o século $X X$, quanto com a cultura agreste do interior do estado. O contato com o interior - levando-lhe os produtos industrializados vindos de fora e escoando os seus produtos - inicialmente era feito pelo transporte fluvial, mas, posteriormente, na primeira metade do século passado, passou a ser feito pelo ferroviário e, mais recentemente, depois da década de 1950, pelo rodoviário (Silva \& Cairo 1997).

Essa característica fez surgir e foi se consolidando, ao longo do tempo, um sítio histórico singular. Em uma área relativamente pequena do tecido urbano, coexiste o modelo luso-brasileiro do início da sua formação, no século XVIII, com a arquitetura oitocentista maranhense e as influências de outras épocas mais recentes, recebidas de outras praças. 
O conjunto das edificações mais antigas de Parnaíba, cuja construção e uso apoiavam-se no regime escravista, está no núcleo original, a maior parte remanescente do século XIX, e teria sido bem maior, de acordo com Silva e Cairo (1997). Foi substituído progressivamente pelo ecletismo do princípio do século XX, em decorrência das relações de produção e consumo, tornando-se o fator mercantilista determinante na sua configuração urbanística desde o seu início. Primeiramente, a substituição foi provocada pelo crescimento do comércio de exportação e importação, que atinge o apogeu durante a Segunda Guerra Mundial e, mais recentemente, por novo surto de expansão desse setor. O fim do ciclo da cera de carnaúba, logo depois da Segunda Guerra Mundial, provoca a perda do dinamismo econômico na região.

Às margens do rio estão os galpões portuários, construídos em alvenaria de pedra e cal de conchas, referências dos primeiros tempos. Próximo dali, a cerca de 300 metros de distância, situa-se a Praça da Graça, com suas duas igrejas assinaladas em documentos do final do século XVIII, ainda hoje existentes, apesar de bastante modificadas. No seu entorno, o arruamento, também remanescente do núcleo original e mais antigo, algumas ruas com sobrados e casas térreas coloniais.

Para Figueiredo e Monteiro (2008: 121), a estagnação do crescimento econômico de Parnaíba não agiu a favor da permanência dos padrões de ocupação que consolidaram o sítio histórico. Por outro lado, "agiu na imobilização dos habitantes em relação ao reconhecimento desse sítio como seu 'lugar', algo que lhes pertencia ou que lhes dizia respeito, lugar de vivência afetiva".

\section{Metodologia}

O artigo tem por objetivo geral descrever o projeto "Prazer em Conhecer, Orgulho em Preservar", apresentando a educação patrimonial como uma ferramenta importante no processo de preservação e conservação do patrimônio edificado. Caracteriza-se como uma pesquisa de cunho qualitativo, com o aporte de fontes bibliográficas e documentais e tem sua análise ancorada nos pressupostos da análise de conteúdo (Bardin, 2011), auxiliada por registro fotográfico e observação participante.

O projeto "Prazer em Conhecer, Orgulho em Preservar", em sua totalidade, teve como objetivo primordial averiguar o significado do patrimônio para estudantes de escolas públicas e particulares da cidade de Parnaíba/Piauí, a fim de compreender o que o discente reconhece como importante para a sua identidade cultural. Diante desse conhecimento, buscou desenvolver ações de educação patrimonial que visaram (re)aproximar o cidadão da sua história, (re)criando laços de pertencimento para com o patrimônio estudado. Foi dividido em etapas, tendo como projeto-piloto a experiência que serve de análise neste artigo.

Contemplou pesquisas de campo por meio da prática do turismo pedagógico e/ou aulaspasseio, com roteiros montados a partir dos bens culturais elencados pelos discentes na pesquisa inicial. Como resultados, o projeto propõe, a partir da análise dessa experiência-piloto, a elaboração de cartilhas educativas, mostras fotográficas e relatórios documentais com os registros históricos dos patrimônios visitados e pesquisados. Pretende ainda, a partir dos resultados encontrados, pensar a elaboração de roteiros culturais para públicos diversos que contemplem os patrimônios eleitos pelos partícipes como representantes da sua identidade cultural, incentivando o uso de tais roteiros pelas agências de viagens receptivas da cidade.

\section{Análise do Projeto 'Prazer em Conhecer, Orgulho em Preservar'}

O projeto foi desenvolvido em Parnaíba entre os meses de Novembro de 2014 e Agosto de 2015, tendo nesta primeira etapa o objetivo de averiguar o significado do patrimônio para estudantes de uma escola pública da cidade, a fim de compreender o que os discentes reconheciam como importante para a sua identidade cultural. Diante desse conhecimento, buscou preparar ações de educação patrimonial que visaram (re)aproximar o aluno da sua história, (re)criando laços de pertencimento para com o patrimônio estudado. Dentre as diversas ações, foram escolhidas: pequenas palestras e dinâmicas em sala de aula, visita guiada pelo conjunto histórico e registro fotográfico da experiência. Os registros dos bens elencados foram feitos pelos discentes, que compuseram uma Mostra Fotográfica exposta na escola e na Superintendência de Cultura do município durante a $13^{\text {a }}$ Semana de Museus ${ }^{3}$, divulgando o projeto e os bens culturais para a sociedade.

3 A Semana de Museus é um evento anual realizado pelo Instituto Brasileiro de Museus (IBRAM), com o apoio dos governos estaduais e municipais. Para mais informações, consultar: http://www.museus.gov.br/ acessoainformacao/acoes-e-programas/semana-nacional-de-museus/ 
A Escola Municipal Professor João Campos, onde as ações se desenvolveram, foi escolhida em função da sua localização, por estar inserida na zona onde estão os conjuntos históricos tombados na cidade, fazendo com que os alunos convivam diariamente com o patrimônio edificado da região. O projeto contou com uma coordenadora, professora do Curso de Turismo da Universidade Federal do Piauí, e seis bolsistas voluntários, alunos do referido Curso, os quais eram multiplicadores das informações e condutores da visita guiada.

A metodologia utilizada para a elaboração dessa primeira etapa do projeto foi baseada em estudo de caráter exploratório-descritivo. O método descritivo pode ser entendido como aquele que tem como objetivo a descrição das características de determinada população ou fenômeno (Martins, 2004). Exploratório, visto que teve o propósito de conhecer a realidade da zona histórica tombada em Parnaíba, no tocante ao seu estado de preservação/ conservação. A coleta de dados foi feita por meio da análise de documentos, pesquisa histórica, comparação de fotografias antigas com atuais para que fossem traçados os panoramas de análise, bem como foi realizado previamente um diálogo com professores e direção da escola para se apropriar da realidade ensino/aprendizagem nas séries escolhidas. Optou-se por trabalhar nesta fase com alunos do $5^{\circ}$ ano do ensino fundamental, por ser a única turma da escola cujos professores disponibilizaram-se a participar.

O foco das ações neste primeiro momento foi a transmissão de conceitos básicos sobre educação patrimonial, patrimônio e identidade cultural, preservação e conservação, propondo uma reflexão junto aos participantes (alunos e professores), distribuídos ao longo de 5 encontros, como apoio à formação da consciência destes alunos sobre a responsabilidade para com a preservação do patrimônio e (re)construção e resgate de sua cidadania.

A educação, vista num sentido mais amplo, é o "processo de desenvolvimento da capacidade física, intelectual e moral da criança e do ser humano em geral, visando à sua melhor integração individual e social". A educação patrimonial, interpretada por Horta (1999: 6) como "um processo permanente e sistemático de trabalho educacional centrado no Patrimônio

4 Dicionário Aurélio Básico da Língua Portuguesa. Rio de Janeiro: Nova Fronteira, 1988: 234.
Cultural como fonte primária de conhecimento e enriquecimento individual e coletivo", tornase forte instrumento no processo de reencontro do indivíduo consigo mesmo, resgatando sua autoestima por meio da revalorização e da reconquista de sua própria cultura e identidade, ao perceber seu entorno e a si mesmo em seu contexto cultural, transformando-se em principal agente de preservação, pois o "conhecimento crítico e a apropriação consciente pelas comunidades do seu patrimônio são fatores indispensáveis no processo de preservação sustentável desses bens, assim como no fortalecimento dos sentimentos de identidade e cidadania." (Idem, 1999: 6)

Ao final dos cinco encontros, percebeu-se a retomada de tais conceitos e a compreensão referente à importância desse processo a partir do envolvimento dos alunos e dos professores e seu interesse em desenvolver as ações propostas, como a visita guiada pelos patrimônios considerados pela turma como representativos da sua identidade. Foram apresentados aos alunos os seis conjuntos que compõem o Conjunto Histórico e Paisagístico de Parnaíba tombados pelo IPHAN $\mathrm{e}$, a partir destes foram elencados os bens a serem estudados e fotografados. Após a coleta de tais informações, foi definida a rota a ser percorrida ao longo do passeio com os alunos, tendo como pontos de partida e chegada a escola, abrangendo o maior número de elementos patrimoniais possível dentro do tempo disponibilizado pela escola.

Para Kossoy (2001), a fotografia é, ao mesmo tempo, uma forma de expressão e um meio de informação e comunicação a partir do real, portanto um documento da vida histórica. Assim, com os propósitos de estimular o interesse e provocar formas de conhecimento em torno da história da cidade de Parnaíba contadas por meio do conjunto histórico visitado, motivando os jovens a construírem subjetiva e objetivamente atitudes e competências para atuarem como cidadãos reflexivos, críticos e comprometidos com o ambiente em que vivem, a fotografia se constituiu em meio para a ampliação da percepção estética e criativa sobre os lugares, as paisagens sociais, arquitetônicas, naturais, culturais exploradas.

Tal proposição, aliada às discussões geradas em sala de aula anteriormente à visitação, contribuiu para uma análise crítica referente ao patrimônio visitado, seu estilo, suas características e seu atual estado de conservação, bem como suscitou questionamentos sobre de que maneira cada aluno 


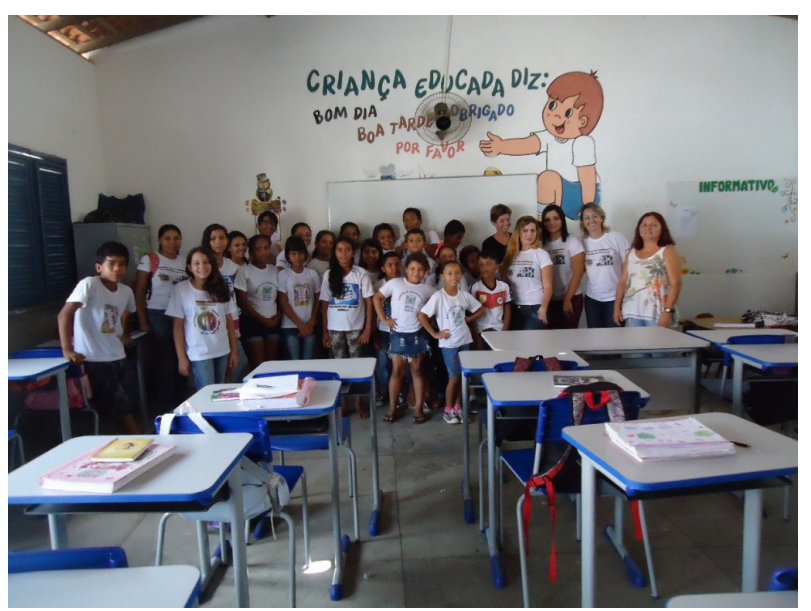

Figura 1: Encerramento dos encontros com a turma da Escola Prof. João Campos

Fonte: Janaina Leocadio, 2015

poderia influenciar direta e indiretamente no processo de salvaguarda do seu patrimônio, indo ao encontro do que Bou (2012, p.173) sugere:

También es conveniente que se promuevan herramientas sociales de acercamiento del património local, tales como seminarios, charlas, rutas guiadas, exposiciones fotográficas, etc. que ayuden a identificar acciones agresivas fáciles de reconocer porque el arte local les es más familiar y por tanto, la sensibilización es mayor para despertar esse sentimiento de pertenencia.

A conclusão desta primeira etapa do projeto concretizou-se em dois momentos: a análise da visita guiada com as discussões supracitadas e a escolha das fotografias que melhor representaram a experiência e a exposição destas na Mostra Fotográfica "Um olhar sobre o patrimônio de

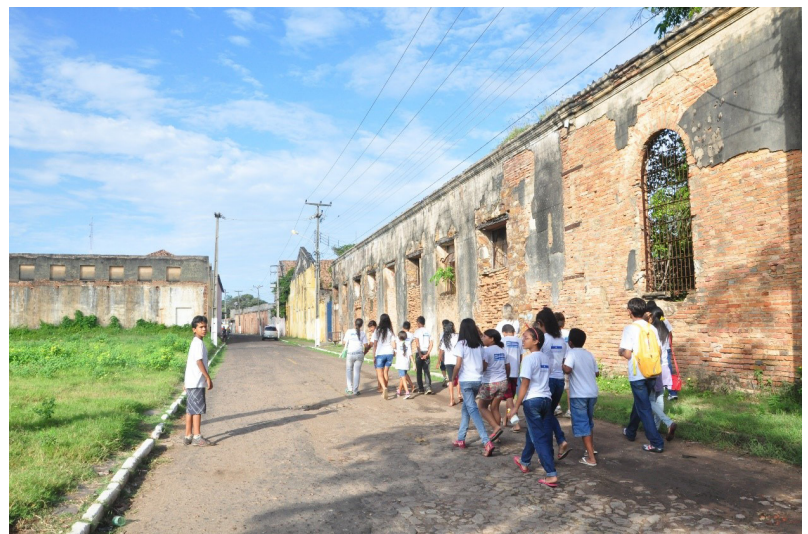

Figura 2: Caminho da escola às ruínas do Porto das Barcas

Fonte: Janaina Leocadio, 2015
Parnaíba”, exposta no museu Casa Grande de Simplício Dias ao longo da $13^{\text {a }}$ Semana de Museus, realizada entre os dias 18 a 24 de maio de 2015 . O resultado positivo dessa intervenção fotográfica permitiu que a exposição fosse estendida para além da programação previamente definida, permanecendo à disposição no museu até as festividades em comemoração ao aniversário da cidade, ao longo do mês de Agosto de 2015.

Com este tipo de estratégia, buscou-se sensibilizar o público visitante sobre a realidade do patrimônio local, despertando o interesse por maiores informações, divulgando a iniciativa e instigando a administração pública a gerir de uma melhor forma os recursos patrimoniais que dispõe, assim como foi possível atrair a atenção para os patrimônios expostos que se encontravam em situação delicada no tocante ao seu processo de conservação. Sendo assim, fortaleceu o diálogo entre a educação patrimonial e a conservação do patrimônio, dando importantes passos rumo a reflexões mais consistentes sobre o patrimônio da cidade.

Apartirdoprojetoapresentado, outrasiniciativas foram surgindo e vem sendo desenvolvidas, por exemplo, pela Superintendência de Cultura do município, tais como a campanha "Pra você, o que identifica Parnaíba?”, que tem como intuito saber a opinião do parnaibano quanto à sua identidade cultural, a fim de "reforçar a revalorização do patrimônio cultural e promover a consolidação da identidade da sociedade" a partir da criação de um museu, expondo ali o que possa representar a história do povo parnaibano e, consequentemente, a história da cidade. A pesquisa, difundida nas redes sociais da prefeitura (Facebook e Instagram, especificamente), foi iniciada em Janeiro de 2016. No entanto, em virtude das novas eleições e de uma nova gestão à frente do governo municipal desde o início de 2017, estas ações estão temporariamente suspensas e sem previsão para serem retomadas.

A responsabilidade que se assume como profissionais e como cidadãos no processo de fortalecimento e revitalização da cultura, e a compreensão dessa atividade como um poderoso instrumento de fortalecimento cultural suscitam uma reflexão sobre a responsabilidade de conduzir os indivíduos no caminho do entendimento e do comprometimento na construção de seu universo sociocultural. Lidar com o patrimônio é lidar com o espelho do país refletido na precariedade com que seu patrimônio se mantém, mas 


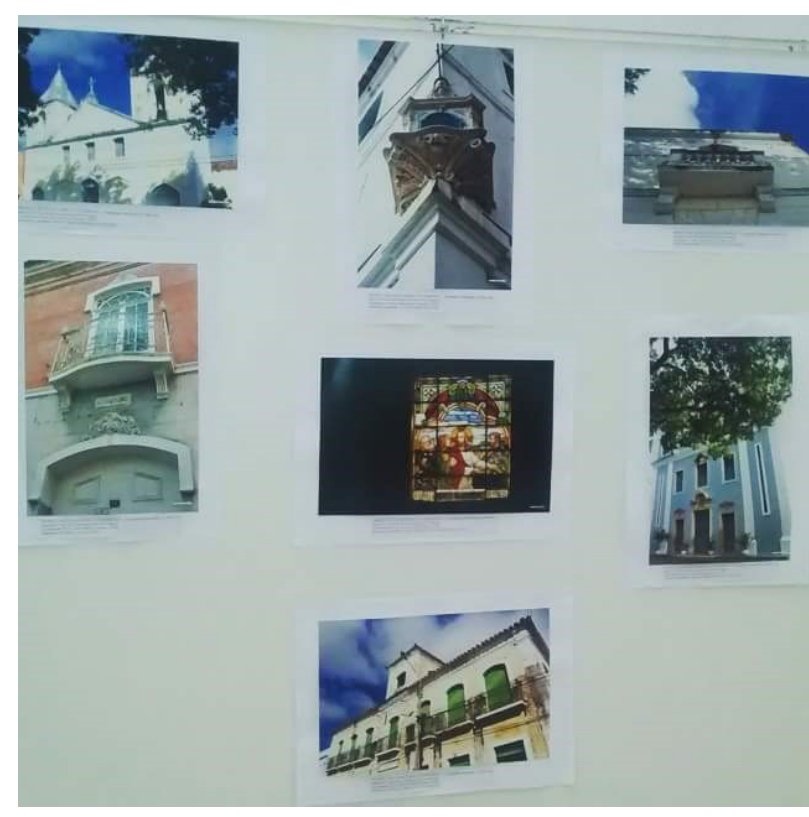

Figura 3: Mostra Fotográfica "Um olhar sobre o patrimônio de Parnaíba" na $13^{\text {a }}$ Semana de Museus

Fonte: A autora (2015)

também é perceber que o saber torna-se mais um instrumento gerador de novas informações e estímulos, pois a possibilidade de se estabelecer uma reciprocidade para com o meio torna o saber específico coerente e construtor, recebendo resposta imediata do ambiente e de seu grupo. A postura que se toma diante do meio em que se atua transforma-o, propiciando a transformação da própria sociedade e, com a participação dos educadores e das administrações locais, deve-se construir uma democracia participativa em que os cidadãos também se corresponsabilizem, já que se convertem em uma fonte de informação privilegiada.

\section{Considerações finais}

Neste artigo, buscou-se apresentar a primeira etapa do projeto de educação patrimonial "Prazer em conhecer, orgulho em preservar" como uma ferramenta possível a ser utilizada para minimizar os problemas no tocante à preservação e à conservação dos bens culturais, em especial o patrimônio edificado. Compreende-se que a educação e a sensibilização para o patrimônio local podem mostrar-se como um importante passo para que o cidadão tome consciência sobre o patrimônio local que dispõe para evitar que a modernização e o progresso possam destruí-lo.

Ainda que o projeto esteja em sua fase inicial, apresenta resultados interessantes a partir do momento em que suscita questionamentos sobre o estado atual do patrimônio parnaibano por parte dos alunos que compuseram a experiência, implicando discussões sobre como podem ser mais atuantes dentro deste processo e o que lhes falta conhecer e reconhecer na cidade onde vivem, bem como por instigar o surgimento de novos projetos, a exemplo do que vinha sendo desenvolvido pela Superintendência de Cultura da cidade entre os anos de 2015 e 2016.

Um dos desafios que se apresenta para a continuação dessas ações é a iniciativa de reintroduzir o conceito de pertencimento com relação ao patrimônio local e despertar a consciência de que qualquer dano causado a ele repercutirá diretamente na qualidade de vida desses cidadãos, pois estará afetando a sua identidade cultural. Estender as propostas das atividades de educação patrimonial não apenas para os alunos, mas para a comunidade de modo geral, faria com que o habitante fosse conhecedor da história de sua cidade e, mesmo que não interaja com ela de maneira próxima, pode vir a desenvolver a capacidade de transmiti-la àqueles interessados em saber um pouco mais sobre os acontecimentos e suas significações para a formação municipal. Dessa forma, o indivíduo pode contribuir com o processo de interpretação patrimonial, uma vez que ele também imprime suas convicções a respeito do seu espaço de vivência, transformando-se em um agente ativo a contribuir com a conservação e com a apreservação dos espaços de memória.

Compreender que a preservação do patrimônio arquitetônico pressupõe um trabalho em equipe e uma responsabilidade compartilhada é de suma importância para que novas ações possam ter êxito e atingir os resultados esperados, ainda que não se trate especificamente de uma coleção ou de um espaço físico, mas sim de um conjunto maior e mais complexo, incluindo o patrimônio nas suas vertentes materiais, imateriais e naturais.

Por fim, a preservação e a conservação desses testemunhos do passado se revela importante também para a atividade turística, pois não se pode pensar em potencializar o turismo em local que é descrente de si mesmo. A partir do momento em que se investiga/apreende, documenta/interpreta, intervem/preserva, informa/difunde o patrimônio de uma determinada localidade, ele pode ser transformado em atrativo a ser conhecido, compreendido e valorizado também pelas pessoas 
que o visitam. E a sustentabilidade dessa atividade só pode ser alcançada com o envolvimento dos visitantes e da comunidade nesse processo de preservação, pois é importante perceber a necessidade de associação entre a interpretação e o atrativo e desses à realidade social para possibilitar a sustentabilidade de ambos. Com o intuito de desenvolver o turismo cultural para a própria comunidade local, surge o conceito de Turista Cidadão (Gastal; Moesch, 2007), que se adéqua ao estudo que se propôs neste artigo. A discussão sobre turismo e cidadania parte da necessidade de aproximação da comunidade junto a sua cidade e seu objetivo é o de fazer com que haja uma apropriação e valorização por parte da comunidade de espaços que até então passam despercebidos e que só são visitados por turistas, a exemplo do que ocorre no conjunto histórico de Parnaíba. Desse modo, para que essa prática de apropriação e interação com o espaço aconteça, é preciso o incentivo dos órgãos públicos e de instituições de ensino, com a criação de projetos que levem essas pessoas a conhecer esses espaços e com a realização de oficinas de educação patrimonial para que elas saibam a importância e a riqueza cultural do seu patrimônio. Foi neste sentido que se inseriu o projeto descrito neste artigo.

Para tanto, visando sensibilizar a comunidade local, os roteiros turísticos também podem ser utilizados como técnicas para a interpretação patrimonial, devido a sua capacidade em revelar significados da herança cultural. Partindo desse pressuposto, a interpretação patrimonial é fundamental para auxiliar as relações de pertencimento dos indivíduos e grupos sociais com o seu patrimônio, uma vez que permite aos mesmos o conhecimento de informações relevantes e significados sobre os bens. Para Murta e Goodey (2002), interpretar o patrimônio referese à prestação de informações e representações que destacam a história e a cultura de um lugar, agregando valor à experiência do visitante. No entanto, utilizando-se de ferramentas e meios para atingir seus objetivos, a interpretação transcende a informação, podendo assim sensibilizar os indivíduos a preservarem os seus patrimônios. Para os autores citados, mais do que informar, "interpretar é revelar significados, é provocar emoções, é entreter e inspirar novas atitudes no visitante, é proporcionar uma experiência inesquecível com qualidade." (Murta \& Goodey, 2002: 14). Desse modo, a interpretação mostra-se de suma importância para o processo de histórico-aprendizado.

Por fim, a educação patrimonial apresentase como uma ferramenta essencial, que pode se constituir em ação pedagógica que busque alcançar a valorização e a preservação do patrimônio cultural legado por determinada comunidade. Assim, a interpretação e a educação patrimonial buscam a sensibilização do coletivo por meio do despertar de sua identificação e pertencimento cultural, para que estes passem a preservar o que lhes foi herdado e, por conseguinte, legá-lo também para as futuras gerações, por forma de herança e direito.

\section{Referência Bibliográfica}

Araújo, A. B. (2007). Carta internacional do turismo cultural. Adoptada pelo ICOMOS, 12a Assembleia Geral no México, 1999.

Bardin, L. (2011). Análise de conteúdo. Lisboa: Edições 70 .

Barreto, E. A. (2010). Patrimônio cultural e educação: artigos e resultados. Goiânia: Universidade Federal de Goiás.

Barretto, M. (2006). Manual de iniciação ao estudo do turismo. São Paulo: Papirus Editora.

Bou, A. P. (2012). Estrategias, proyectos y nuevas vías de actuación para una conservación y restauración responsable com el património cultural local. In $V$ Congresso Patrimonio Cultural Criterios de Calidad en Intervenciones. Grupo Español IIC, Universidad Complutense, Madrid.

Canclini, N. G. (1999). Los usos sociales del património cultural. In: Aguilar, E. (org.). Patrimônio Etnológico: Nuevas perspectivas de estúdio. Sevilla: Consejería de Cultura. Junta de Andalucía.

Carvalho, P. (2012). Património cultural, ordenamento e desenvolvimento: uma nova visão e valorização do território. In P. Carvalho; J. L. J. fernandes. Património cultural e paisagístico. 14-37. Coimbra: Imprensa da Universidade de Coimbra.

César, P. A. B.; Stigliano, B. V. (2010). A viabilidade superestrutural do patrimônio: estudo do Museu da Língua Portuguesa. CULTUR - Revista de Cultura e Turismo, ano 4, n. 01, Ilhéus, Bahia. ISSN: 1982.5838

Choay, F. (2015). A alegoria do patrimônio. São Paulo: Unesp.

Costa, F. R. (2009). Turismo e patrimônio cultural. São Paulo: SENAC.

Da Costa, P. (1974). Cronologia histórica do estado do Piauí. Rio de Janeiro: Editora Artenova. 
Fernandes, J. R. O. (1993). Educação Patrimonial e Cidadania: uma proposta alternativa para o Ensino de História. Revista Brasileira de História. São Paulo, 13 (25-26), 265-276.

Figueiredo, D. M. F. (2001). O monumento habitado: a preservação de sítios históricos na visão dos habitantes e dos arquitetos especialistas em patrimônio. O caso de Parnaíba. Dissertação de Mestrado em Desenvolvimento Urbano, Centro de Artes e Comunicação (CAC), Universidade Federal de Pernambuco, Recife.

Figueiredo, D. M. F. \& Monteiro, C. M. G. (2008). A experiencia do ambiente na preservação do sítio histórico de Parnaíba. Revista Vivência, 34, 19-142.

Gastal, S. \& Moesch, M. (2004). Um outro turismo é possivel. São Paulo: Contexto.

Gastal, S. \& Moesch, M. (2007). Turismo, políticas públicas e cidadania. São Paulo: Aleph.

Gomes, M. S.; Santos, C. M.; Vasconcelos, C.: Aragão, H.; Britto, S. \& Andrade, T. (2015). Turismo cultura, educação patrimonial e cidadania: Uma experiencia entre Universidade, escola e museu em Sergipe. Revista Rosa dos Ventos - Turismo e Hospitalidade, 7(3), 459-470.

Guichen, G. de. (1999). La conservacion preventiva: simple moda pasajera o cambio transcendental? Boletim da UNESCO, n. ${ }^{\circ}$ 201, 51 (1).

Horta, M. L.P., Grunberg, E. \& Monteiro, A. Q. (1999). Guia Básico de Educação Patrimonial. Brasília: Instituto do Patrimônio Histórico e Artístico Nacional, Museu Imperial.

Kossoy, B. (2001). Fotografia \& História. 2. a ed. rev. São Paulo: Ateliê Editorial.

Krippendorf, J. (2003). Sociologia do Turismo: para uma nova compreensão do lazer e das viagens. São Paulo: Aleph.

Lemos, C. A. C. (1982). O que é patrimônio histórico. São Paulo: Editora Brasiliense.
Martins, G. A. (2004). Manual para elaboração de monografias e dissertações. 2. ${ }^{\mathrm{a}}$ ed. São Paulo: Atlas.

Mendes, J. A. (2009). Estudos do património: Museus e educação. Coimbra: Imprensa da Universidade de Coimbra.

Meneses, U. T. B. (1999). Valor cultural, valor econômico: encontros e desencontros. II Seminário Internacional de História de Energia, Fundação Patrimônio Histórico da Energia de São Paulo, 30-44.

Mott, L. R. B. (1985). Piauí colonial: população, economia e sociedade. Teresina: Projeto Petrônio Portela.

Motta, M. M. M. (1998). História e Memórias. In Mattos, M. B. (org.). História - pensar \& fazer. Niterói: LDH/UFF, 72-89.

Murta, S.M.\& Goodey, B. (2002). Interpretação do patrimônio para visitantes. In Murta, S.M. \& Albano, C. (orgs). Interpretar o Patrimônio: um exercício do olhar. Belo Horizonte: Ed. UFMG.

Oriá, R. (2001). Memória e Ensino de História. In Bittencourt, C. (org.). O Saber Histórico na Sala de Aula. 5. ${ }^{a}$ ed. São Paulo: Contexto.

Sarmento, A. G. S. (2003). Preservar para não restaurar. In Simpósio Internacional de propriedade intelectual, informação e ética: anais, 2. Florianópolis: Associação Catarinense de Bibliotecários.

Scifoni, S. (1996). A construção do patrimônio natural. Tese do Doutorado em Geografia, Faculdade de Filosofia, Letras e Ciências Humanas, Universidade de São Paulo, São Paulo.

Silva, O. P. \& Cairo, C. (1997). Inventário de proteção do acervo cultural do Piauí: Parnaíba. v.3. Teresina.

Tuan, Y. F.(1983). Espaço e lugar: a perspectiva da experiência. Trad. Lívia de Oliveira. São Paulo: Difel.

Contribuição dos autores na construção do artigo

KANITZ: Artigo completo. 